\title{
Los cursos sudamericanos de Verano de Montevideo y la delegación Universitaria de San Marcos.
}

La prensa nacional y extranjera y los servicios de las agencias noticiosas han informado ya a nuestro público acerca del desarrollo del importante acontecimiento educativo y cultural que, aliniciativa del Ministro de Educación Pública del Uruguay se realizó en la capital de esta República hermana, de Enero a Febrero del año en curso. Se ha podido seguir así en nuestro país la realización de los primeros Cursos Universitarios Sudamericanos de Vacaciones, ya que hace algún tiempo vienen efectuándose en diversas Capitales de nuestro Continente, como Santiago, Panamá y México, Cursos Universitarios de Verano, los cuales, aún cuando han contado con la colaboración de profesores extranjeros, no se han inspirado en el propósito de acercamiento universitario inter-continental que animó a los que acaban de celebrarse en Montevideo.

La información recibida con respecto a esta primera Universidad Veraniega Sudamericana--pues tales han sido la significación y magnitud positivas de los menciona- 
dos Cursos-fué, sin embargo, general y, por decirlo así externa. Los corresponsales y reporteros, atentos antes a la novedad del evento que a su significado y trascendencia culturales, no han puesto en relieve éstos. Las siguientes líneas vienen a subsanar esta deficiencia y a hacer hincapié acerca de ciertos aspectos y momentos de la reunión interuniversitaria del Uruguay, que interesan a la vida espiritual así como a la solidaridad latinoamericanas.

Desde luego, la idea y el propósito-ampliamente realizados-de estrechar los vínculos fraternales que unen a las repúblicas sudamericanas mediante un intimo contacto espiritual, el de los estudiantes y maestros, representantes los más calificados de nuestras naciones, y mediante el intercambio de las lecciones que aprenden y enseñan con respecto a tres direcciones fundamentales de su realidad nacional: la histórica, la literaria y la económica, constituyen aporte verdaderamente sustancial al ideal de la unión latinoamericana y al anfrelo y necesidad de acercamiento y complementación recíprocos que se siente hondamente en nuestros paises.

Hace un "cuaftoPdesigilolios miversitarios latinoamericanos quisieron satisfacer aquel anhelo y esa necesidad mediante la celebración de Congresos Internacionales de Estudiantes, en cuyas asambleas los representantes estudiantiles de nuestras Universidades al mismo tiempo que aproximarían al través de sus vínculos personales e institucionales sus patrias hermanas, plantearian y estudiarían juntos sus problemas comunes y procurarían buscarles solución en un ambiente de armonía y unión continentales. Tales Congresos a parte del acercamiento estudiantil y la curiosidad que suscitaron por las respectivas patrias fraternas, no dejaron, desvanecido ya el ambiente momentáneo de cordialidad y simpatía que causaron, sino un puñado de entusiastas mociones y generosos votos en pro de la solida- 
ridad americana que se confundieron en el caudal de análogos entusiasmos generosos.

Los Cursos Universitarios Interamericanos persiguen una finalidad no menos noble, pero la realizan en terreno más práctico y fecundo: en el de la docencia superior profesada por maestros de la Universidad de nuestra América ante públicos formados por elementos representativos no sólo de los claustros universitarios y escolares sino de los diversos sectores de la intelectualidad y del pensamiento de los países donde se efectúan, en conformidad con programas orgánicos que consultan tanto la eficacia de la enseñanza, cuanto el intercambio, la cooperación y la armonía entre quienes la imparten y entre éstos y quienes la reciben.

La eficacia de esta nueva forna de acercamiento latinoamericano por los cauces universitarios ha quedado demostrada en los iniciales Cursos Sudamericanos Universitarios de Montevideo. Los brganizadores de éstos procuraron-y lo consiguieron-darles toda la seriedad y el carácter de la enseñanza universitaria, así en la redacción del Programa como enBéloesstrictocy puntial tcumplimiento del mismo, y no omitieron esfuerzo pata brindar al público oyente las mayores facilidades de asistencia. Por su parte los profesores invitados y concurrentes, representantes de las Universidades de Argentina, Brasil, Chile, Ecuador, Paraguay, Perú y Uruguay correspondieron a la honrosa invitación, dictando su lecciones en conformidad con el Programa y facilitando a su auditorio las fuentes de información y consulta respectivas.

Más de treinta profesores universitarios, entre los cuales destacáronse figuras de prestigio continental como José Gabriel Navarro, Carlos Reyles, Gabriela Mistral, Alberto Zum Felde, Pérez Petit, Roberto Levillier, Giménez Pastor, Gómez Haedo, dieron más de cien clases de Historia. Literatura y Ficonomía de sus países a un auditorio mayor 
de mil personas, que, desde el comienzo hasta el fin de los Cursos las escuchó con interés y entusiasmo, colmando las aulas del Instituto Vásquez Acevedo donde se dictaron.

Al servicio de información y conocimiento recíprocos que prestaron estas lecciones, vino a sumarse el representado por el acercamiento entre los profesores universitarios y entre éstos y sus auditorios. Desde el principio aquéllos viéronse rodeados por un ambiente de interés y simpatía que no decayó un momento y que fué el clima propicio para la eficacia de los Cursos. En efecto, superando con mucho las expectativas de sus organizadores y colaboradores, las aulas de clases fueron ocupadas día tras día del período universitario de Vacaciones por un público escogido y copioso, formado por maestros universitarios, normales y secundarios, escritores, periodistas, alumnos de los grados superior y secundario y por particulares, sinceramente interesado en las materias que se enseñaban, público fiel y fervoroso que, al terminar la clase rodeaba la cátedra para pedir al profesor datos e informes ampliatorios de su lección. La comunidad en da docenciacestableció desde el primer momento Júnculos drofundos entre los profesores, cuyas clases se entrelazaban en el Programa, vinculación provechosa y fecunda para ellos y para las Universidades que representaban y que, desde luego, se tradujo en intercambio de programas, métodos de enseñanza y bibliografía y en un firme propósito de incorporar a sus claustros respectivos los elementos de progreso y perfeccionamiento existentes en los ambientes universitarios hermanos.

Los personeros más calificados de la intelectualidad uruguaya, aparte del elemento pedagógico rodearon a los delegados sudamericanos, alternaron con ellos en la cátedra y se apresuraron a obsequiarles sus libros, a agasajarlos en sus círculos y a pedirles informes acerca del movimiento intelectual en sus países respectivos. Entre esos al- 
tos representantes de las letras uruguayas destacáronse personalidades como Juana de Ibarbourou, la eminente poetisa, gloria de América, quien extremó sus atenciones y finezas con nuestra delegación, obligando su especial reconocimiento; Alberto Zum Felde, considerado como el critico más notable de la literatura uruguaya; Sara Bollo y Ester de Cáceres, distinguidas poetisas; 'Manuel de Castro, periodista y novelista de relieve; Carlos Reyles, el celebrado autor de "El Embrujo de Sevilla"; Eugenio Petit Muñoz, autorizado crítico; Carlos Sábat Pébet, ensayista fino y profundo; Manuel Pinto y Blas Genovese, poetas inspirados de la nueva generación; Orestes Baroffio, erudito periodista y exquisito ingenio y un grupo de escritores y artistas de verdad y porvenir que componen el cenáculo de la vigorosa personalidad aninadora de la Señora de Müller.

Tanto la inauguración como la clausura de los Cursos fueron ceremonias muy solemnes, realizadas con la presencia de las autoridades politicas, docentes e intelectuales del Uruguay y la de un público tan escogido como numeroso. En el primero de los actos referidos tocó al Presidente de nuestra delegación, doctor fuis Valcárcel, entre sus colegas de representacion, pronunciar las siguientes palabras, que fueron muy aplaudidas:

Señor Ministro, señores:

Portadores de un mensaje de encendida fraternidad, venimos desde el Perú, como hermanos vuestros, distantes, casi quiméricos, y es como hijos espirituales de la más vieja universidad del continente, la de Lima, que gozamos del privilegio de llamarnos vuestros huéspedes.

Largo es el camino recorrido hasta aquí. El océano, la cordillera, los valles, la pampa, el río, los accidentes todos de nuestra América, se oponían como para haceros más deseables. Loos hemos vencido y un día llegamos a vuestras playas que se llaman ramblas y nó fortalezas tan generosos y fraternos sóis. 
Llegamos a la tierra suave, de leves ondulaciones, en la que el cerro, el mar y el río, jugando alegremente, componen el paisaje uruguayo, que es el paisaje de vuestra serenidad. Gran símbolo de vuestro espíritu de luminosa tolerancia. En el Pacífico, os imaginamos un pueblo idealista de poetisas y pensadores y, por vuestro humanismo tan arraigado, todos los corazones, como agujas imantadas, señalan vuestro norte. $Y$ aquí nos tenéis, atentos a la voz de orden, en esta salvadora cruzada de entendimiento americanista, nunca como ahora más necesario, cuando se ciernen sobre nuestro límpido cielo pavorosos peligros. Nuestro espíritu vigilante, preparado en el esfuerzo heroico, percibe ya que otras jornadas de emancipación comienzan para la América.

Seamos dignos de la hora, olvidando lo particular y accidental para confundirnos en el sentimiento de responsabilidad histórica que gravita sobre nuestras generaciones. Essuchando la voz augusta de nuestros Libertadores, sabremos eumplir nuestro deber.

Presente está el Perú en esta cita de honor.

Aunque la Universidad Nacional de Montevideo no intervino en la organización de los Cursos Sudamericanos, su Rector, el eminente maestro y pensador doctor Carlos Vaz Ferreira, tuvo la fineza de invitar a los delegados a una recepción solemine en el Salón del Rectorado y del Consejo Universitario em nombrely porvacuerdo especial de éste. En el acto de recepción de las delegaciones y en presencia de éstas, de los consejeros y catedráticos de la Universidad y de connotadas personalidades universitarias, el doctor Vaz Ferreira pronunció el siguiente discurso:

\section{Señores delegados. Señores:}

EI acto que declaro abierto es una sesión pública del Consejo Universitario, que esta Corporación, unánimemente, resolvió celebrar para recibir a los delegados extranjeros que toman parte en: los actuales Cursos de Vacaciones de nuestro país. La Universidad de Montevideo, aunque no haya sido encargada de la organización de esos cursos, no podía permanecer indiferente a la presencia de personalidades de la significación cultural y precisamente uni- 
versitaria de esos representantes, y ha querido, como ya el Rector que habla tuvo ocasión de expresarlo en una visita que le fué tan grata, poner a disposición de los delegados las distintas reparticiones de la Universidad, facilitándoles el conocimiento de ésta y el relacionamiento con las personas que, entre nosotros, dirigen o imparten la enseñanza superior. Hoy completamos aquella espontánea actitud expresándoles que su concurrencia a este acto nos satisface y nos honra.

Esta es la expresión sencilla y sincera de nuestros sentimientos. EI resto, podría ser oratoria; pero yo no quiero pronunciar aquí discuros, y menos el que cierto protocolo retórico suele imponer para actos como éste: con el tema de la fé absoluta en el porvenir de América, cimentado en la paz y en la libertad, en la unión y en la fraternidad, en la comunidad de aspiraciones orientadas hacia un porvenir de felicidad y progreso tan infaliblemente fatalizado, que permitiría-, y desgraciadamente, cuánto permite!-dejar sustituir el esfuerzo intenso y constante, a la vez fervoroso y aplicado, por sentimientos vagos y fáciles y por su todavía más fácil expresión oratoria...

Ese no puede ser-al menos, no puede ser hoy-el estado de espíritu de los universitarios sudamericanos, ni en general de nadie, que, en este momento crucial, tenga el deber de dar enseñanza y ejemplo en nuestro continente.

Una crisis mundial dolorosa y sombría, no sólo compromete los ideales cuya más plena realización se había podido creer asegurada para un futuro más 0 menos próximo, sino que pone en peligro lo que, de esos ideales, parecía definitivamente adquirido y consolidado.

No creo, entre paréntesis, que sea esencialmente, o principalmente, una crisis moral; no: en esa violencia presente de las luchas ideológicas, sociales, políticas, creo que, con la constante de mal, interfiere por lo menos tanta sinceridad, tanto capacidad de heroismo y sacrificio como en las épocas en que más ha dado la humanidad.

Más bien es crisis de razón y de sentido crítico; están como distorcionados la lógica y el buen sentido; embotada la facultad de pensar a largo plazo, y como vencidas las resistencias que tenían por función defender a los hombres y a los pueblos contra el error y el absurdo: la resistencia a las falacias, a las consignas y a la imitación.

$\mathrm{Y}$ esto último, sobre todo, es lo que pone en peligro a un continente que como nuestra Sud América, ha sido, y ha tenido que ser forzosamente, al principio, un continente imitador.

No estoy pensando en el arte: en ese campo, hace ya tiempo que muestra independencia se afirma, sobre todo porque ni el vaivén de los teorías ni la imitación pueden afectar la aparición y la manifes- 
tación de las personalidades creadoras y primeras, que en arte son todo, y en que, felizmente, nuestros países han sido fecundos.

Y tampoco estoy pensando en la ciencia, pues, en ese otro campo, el proceso es de dirección contínua, colaboración y complementación de personalidades de todos los órdenes intelectuales, y complementación también de la imitación con la originalidad posible, sin oposición ni peligros.

Pero en lo moral, en lo social, en lo internacional, se configura hoy, peligrosa, incierta, una situación cuyo desenlace dista para nosotros de estar asegurado, ya que todo depende de que este continente, acostumbrado a ser imitador, puede hacerse capaz, conquistando con esto otra indepencia, de resistir a la imitación de todo lo que signifique odio, crueldad, regresión, persecución, opresión, intolerancia, hipocresia, sofismas, absurdos, unilateralidades extremistas, exclusivas $y$ hostiles. Y si es capaz de esa resistencia, podrá ser la América en que tan confiadamente esperaron, de consuno, nuestros sentimientos y nuestra razón: y, si no, no será.

Darse euenta de esto: sentirlo y hacerlo sentir : es quitar fé?. No, ciertamente, sino prevenirse contra una fe demasiado fácil e inerte que nos inhiba la voluntad, nos aduerma y nos afloje el esfuerzo. Con todo lo cual se relaciona, precisamente, en este momento, el mayor deber de las Universidades y de los universitarios sudEmericanos. Mayor, nuestra parte, que la de nadie, en esa responsabilidad esencial.

$Y$ por eso yo desearia que alguna vez, en algún momento de nuestros luchas, en esa acción continua, diaria, en que ni siquiera bastan los grandes entusiasmos las virtudes pequeñas son el cemento de las virtudes grandes c tquel lenCalgúm momento, para sobreponernos a alguna derrota o a alguna desilución; son tantas! y tan difícil ser hombre; pero se puede-que alguna vez cada uno de nosotros recuerde este momento en que estuvimos aquí reunidos,no simplemente como el de un frío acto académico en que se pronunciaron algunas frases hechas, sino-y, por poco que valga mi palabra, si ustedes ponen su alma, así será-como una especie de pacto espiritual cuyo recuerdo nos dé un poco más de fuerza en el cumplimiento de nuestro deber de enseñar, en doctrina y ejemplo; para que se sienta que si las Universidades concentran y emiten razón y saber, no es para enseñar a sustituir los entusiasmos idealistas por consideraciones positivas, sino para descubrir $y$ hacer comprender los fundamentos positivos de los entusiasmos y de los idealismos.

En respuesta y en representación de nuestra delegación y de las repúblicas hermanas, el suscrito expresó estos conceptos: 
Señor Rector:

Señores Catedráticos: Señores Delegados: Señores:

Es para mí honor inmerecido y motivo de profunda alegría el traer el saludo de las delegaciones miversitarios latinoamericanas concurrentes a los Cursos de Verano, organizados por el gobierno del Urugnay, a la ilustre Universidad de Montevideo; y con ese saludo el mensaje de amor fraternal de nuestras naciones a la hermana dilecta que en su acrópolis-punto simbólico de confluencia del Plata, que en su aguas acarrea la sustancia de nuestra América y del Atlántico, que en sus ondas nos entrega las simientes, las flores y los frutos de la cultura occidental-custodia, nueva Palas Ataenea, el Tesoro de nuestra cultura, frente a las fuerzas de la barbarie que pretenden asaltarlo y saquearlo.

Con alegría fraterna, con puro júbilo espiritual, venimos a depositar el ósculo familiar de nuestros pueblos, por labios de nuestras Universidades-labios hechos para dar el beso de paz y unión, pero también para proclamar la verdad y defender la justicia-en la noble frente de vuestra Universidad, donde luce con toda su pureza y hermosura el ideal de la vida y de gobierno que os enseñaron comó decálogo inviolable vuestros patricios y vuestros prohombres.

Aquí estamos congregados maestros y discípulos, venidos de todos los puntos de nuestro vasto Continente, de nuestra grande e indestructible hermandad tened por cierto que los $S$ ausentes están presentes en espíritu irestamos deunidos en wuestra ágora luminosa, en torno vuestro, los que, por ejercer el más alto ministerio, es decir servicio social: el de aprender la verdad para enseñarla, somos representantes e intérpretes de las necesidades, de los anhelos, de las aspiraciones de nuestros pueblos, y tenemos la misión sagrada de estudiar esas necesidades, de traducir esos anhelos y de velar porque esas aspiraciones-si propenden al bien común-se realicen y se cumplan al amparo de normas legales, fluyan por anchos cauces, como corrientes de nueva vida a fecundar campos nuevos.

Y hemos venido porque nos habéis llamado, y lo habéis hecho, cumpliendo el mandato augusto que la Historia ha confiado a vuestra patria: ser el lazo espiritual de nuestra hermandad, el centro moral de gravedad de los Andes, de la Pampa y de la Selva, cuyas riquezas culturales habrá de guardar un día vuestro Tesoro de Delfos.

Estamos reunidos aquí los maestros de la América nuestra, de Ia América a la vez milenaria y niña, que crece en su nueva infan- 
tación de las personalidades creadoras y primeras, que en arte son todo, y en que, felizmente, nuestros países han sido fecundos.

Y tampoco estoy pensando en la ciencia, pues, en ese otro campo, el proceso es de dirección contínua, colaboración y complementación de personalidades de todos los órdenes intelectuales, y complementación también de la imitación con la originalidad posible, sin oposición ni peligros.

Pero en lo moral, en lo social, en lo internacional, se configura hoy, peligrosa, incierta, una situación cuyo desenlace dista para nosotros de estar asegurado, ya que todo depende de que este continente, acostumbrado a ser imitador, puede hacerse capaz, conquistando con esto otra indepencia, de resistir a la imitación de todo lo que signifique odio, crueldad, regresión, persecución, opresión, intolerancia, hipocresia, sofismas, absurdos, unilateralidades extremistas, exclusivas y hostiles. $Y$ si es capaz de esa resistencia, podrá ser la América en que tan confiadamente esperaron, de consuno, nuestros sentimientos y nuestra razón: y, si no, no será.

Darse cuenta de esto: sentirlo y hacerlo sentir : es quitar fé?. No, ciertamente, sino prevenirse contra una fe demasiado fácil e inerte que nos inhiba la voluntad, nos aduerma y nos afloje el esfuerzo. Con todo lo cual se relaciona, precisamente, en este momento, el mayor deber de las Universidades y de los universitarios sudamericanos. Mayor, nuestra parte, que la de nadie, en esa responsabilidad esencial.

$Y$ por eso yo desearía que alguna vez, en algún momento de nuestros luchas, en esa acción continua, diaria, en que ni siquiera bastan los grandes entusiasmoselas virtudes pequeñas son el cemento de las virtudes grandes;-que en algún momento, para sobreponermos a alguna "derrota o a alguna desilución;" son tantas! y tan difícil ser hombre; pero se puede-que alguna vez cada uno de nosotros recuerde este momento en que estuvimos aquí reunidos,no simplemente como el de un frío acto académico en que se pronunciaron algunas frases hechas, sino-y, por poco que valga mi palabra, si ustedes ponen su alma, así será-como una especie de pacto espiritual cuyo recuerdo nos dé un poco más de fuerza en el cumplimiento de nuestro deber de enseñar, en doctrina y ejemplo; para. que se sienta que si las Universidades concentran y emiten razón y saber, no es para enseñar a sustituir los entusiasmos idealistas por consideraciones positivas, sino para descubrir y hacer comprender los fundamentos positivos de los entusiasmos y de los idealismos.

En respuesta y en representación de nuestra delegación y de las repúblicas hermanas, el suscrito expresó estos conceptos: 
cia con rapidez asombrosa y en peligro de dejarse extraviar por sugestiones malsanas, en una hora de desquicio y de disolución, en que las bases de la cultura oceidental, desgastadas y carcomidas, parecen negarse a sostener por mucho tiempo más el viejo edificio de Occidente; en que las fuerzas del egoismo primitivo, poniendo en juego ora la astucia, ora lo violencia amenazan con imponer su imperio tenebroso sobre un orden social tambaleante: en que el peso muerto de la inercia y del conservatismo, que suele disfrazarse con los arreos de la renovación para pervivir y seguir dominando y el impulso desaforado de la anarquía y la demagogía, ávidas de poderío, conspiran a una contra la reedificación de la vida social sobre los cimientos de la democracia verdadera. En este momento angustioso para el mundo nos encontramos reunidos en este forum de pensamiento libre los maestros de América, y es una oportunidad brillante que debemos aprovechar para robustecer nuestros víneulos familiares mediante la inteligencia, que es nuestro instrumento de trabajo, y defender nuestra heredad común, que es el humanismo ciemocrático en que vivimos, nos movemos y respiramos.

Porque los maestros - y menos que todos los universitariosno somos ni podemos ser lo que los interesados en impedir que la inteligencia, movida por el sentimiento de justicia y orientada hacia el ideal de verdad, gobierne las sociedades, pretenden que seamos: meros indagadores, archiveros y divulgadores de la ciencia: téenicos y especialistas, encastillados en su técnica y su especialidad; sabihondos en fragmentos de vida, incapaces de seguir y menos aún de encausar las corrientesevitales que renuevan y revifican el organismo de las naciones.

Los maestros debemos ser sabios, sabedores, conocedores y enseñadores de las leyes que rigen el mundo físico y moral; pero debemos ser también sabios, en el sentido oriental, es decir apóstoles y profetas, cruzados y misioneros de la verdad. Debemos ejercer, en suma, el doble ministerio que nos impone nuestra profesión: enseñar la verdad y velar porque se haga carne y sangre y espíritu en nuestros pueblos y velar porque no se corrompa ni se pierda, porque es la sal de la vida, y si se perdiere o adulterare, como dice el Evangelista, đacon qué se salará?

Esa verdad se expresa y se resume hoy en el campo de nuestra organización cuitural en la palabra "democracia", condición primaria de la conservación y sostenimiento de todas las conquistas esenciales que en todos los órdenes de la vida ha alcanzado el hombre. Democracia : esto es, gobierno del pueblo por el pueblo; gobierno en beneficio y provecho de todos los miembros de la sociedad y no en provecho y beneficio de alguno, con exclusión y detrimento 
de los demás. Democracia: es decir, representación efectiva đel pueblo en el gobierno del Estado, a fin de que las necesidades del pueblo sean satisfechas, sus vocaciones puedan realizarse y sus actividades y propósitos se cumplan, en coordinación justa y armoniosa.

Tal es la condición indispensable, la piedra angular y el marco de toda cultura actual; $y$, por tanto es la verdad fundamental que los maestros latinoamericanos debemos enseñar y defender, porque si es atacada y destruída, vacilará y se desplomará el edificio de lá justicia social y sobre sur minas erigirán su imperio voraz y bárbaro los negociantes de la cosa pública, en favor de sí y de sus clientes $\mathrm{y}$ en perjuicio de la comunidad.

He aquí nuestro tesoro délfico, el metal precioso con que forjaron las repúblicas de nuestra patria común sus grandes profetas, soldados y guías; he aquí el legado irrenunciable, el patrimonio maguífico de nuestra raza, el signo de salvación de nuestra América.

En esta hora grave, en que se ve amenazada esa arca de nuestra alianza, ese Paladión de nuestra cultura, acudimos a vuestra Acrópolis vuestros hermanos, los maestros de América Latina, y os decimos: sed beneméritos de nuestra comunidad, porque custodiáis el clepósito sagrado que nos confiaron nuestros padres, aquellos que, por querernos libres y unidos, fraternalmente iguales, lo amasaron con su sangre $y$ con su vida $y$ nos lo dieron como inagotable Fuente de Juvencio, en donde habremos de retemplar nuestras fuerzas; aquí estamos al lado vuestro para ayudaros a defender ese Tesoro, en cumplimiento de nuestra mision y nuestro ministerio, que es estudiar, enseñar y velar en pro de los fundamentos de nuestra cultura!

Señor Rector; Señores Catedráticos:

En nombre de nuestras universidades, cuya delegación ejercemos, y, en especial, de la Mayor de San Mareos, la decana del Continente, abuela de nuestra ciencia y escuela de los pensadores y los héroes que dieron vida a nuestras repúblicas, os agradecemos la cordial acogida y la hospitalidad fraterna que nos dáis en esta joven y ya eminente Universidad, donde representáis tan digna y noblemente la cultura del pueblo uruguayo que es orgullo nuestro.

La prensa de Montevideo comentó en forma muy elogiosa ambos discursos, expresión de la solidaridad de los universitarios latinoamericanos en defensa de las instituciones tutelares de nuestras naciones y los reprodujo en sus columnas. 
Otros actos de significación intelectual y vinculación cultural se realizaron durante los Cursos de Vacaciones, como: una Muestra del Libro Uruguayo, que se efectuó en el local del Instituto Vásquez Acevedo, y que, a iniciativa nuestra y bajo los auspicios del Ministro de Educación Pública del Uruguay y de nuestro Ministro Plenipotenciario en ese país, doctor Luis Fernán Cisneros, cuya proverbial gentileza y dedicación al servicio de las relaciones peruanouruguayas favoreció tánto el desempeño de nuestra misión, habrá de trasladarse en breve a Lima; una Exposición completa de la considerable obra del notable pintor uruguayo Blanes Viale, de la cual se editó un magnífico album; un Concierto de Música Latinoamericana, que se efectuó en el Teatro Ambassador y en el cual se ejecutó en primer lugar algunos fragmentos de un Cuarteto para instrumentos de cuerda de nuestro malogrado compositor Alfonso de Silva; una fiesta de arte peruano que los delegados peruanos ofrecimos en retribución a las atenciones recibidas, a la intelectualidad y sociedad uruguayas, y en la cual presentamos muestras de la jobra de los poetas y músicos jóvenes del Perú; un homenaje a la memoria de Juan Parra del Riego, el vigoroso y brillante poeta peruano, que tan honda huella dejó en su segunda patria, y en que participaron escritores uruguayos y peruanos; un homenaje al vate uruguayo Juan Zorrilla de San Martin y algunas reuniones y recepciones literarias que se efectuaron en diversos círculos y hogares.

Consecuencia de esta primera Universidad Sudamericana de Verano habrán de ser, entre otros acontecimientos de positivo acercamiento espiritual latinoamericano, la redacción de un Tratado de Economía Latinoamericana, a iniciativa de nuestro compañero de delegación el doctor José Valencia Cárdenas; el envío de una Exposición de la Obra Pictórica del genial pintor uruguayo Pedro Figari; 
$-25-$

el de la primera Exposición del Libro Uruguayo y la posible continuación de los Cursos Sudamericanos de Montevideo en Lima, ya que éstos están destinados a realizarse sucesiva y anualmente en las capitales de nuestra América Latina.

Manuel Beltroy. 


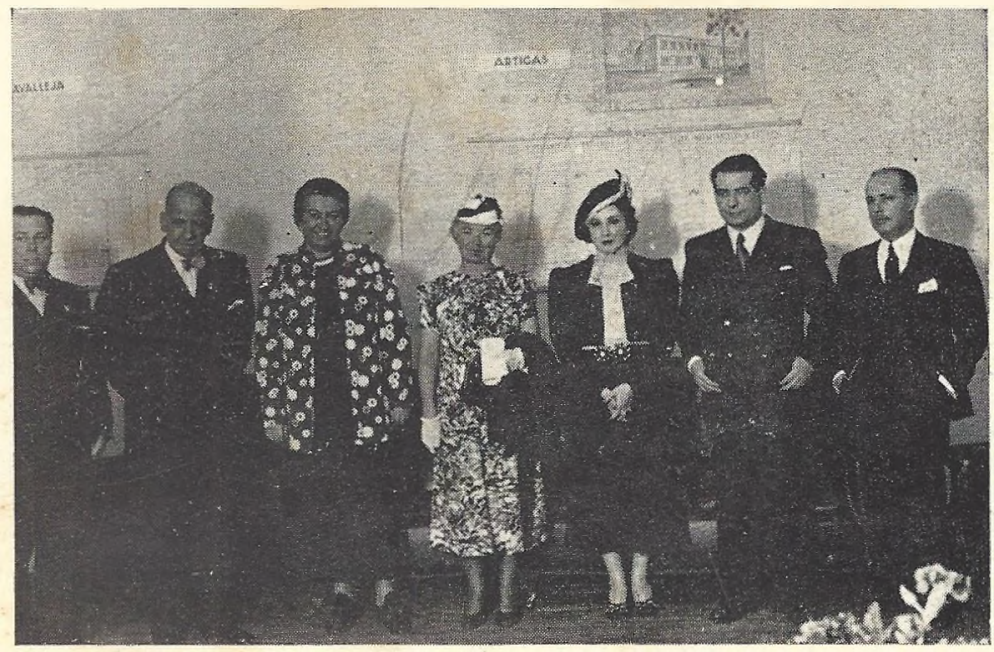

Los Ministros de Instrucción Pública y de Relaciones Exteriores del Uruguay, D. Eduardo Víctor Haedo y Dr. José Espalter, la Sra. Juana de Ibarbourou (Uruguay), Gabriela Mistral (Chile) y Alfonsina Storni (Argentina). El Prof Eduardo de Salterain Herrera, Presidente de la Comisión Organizadora de los Cursos de Vacaciones e Inspector José Pereira Rodríguez (Uruguay).

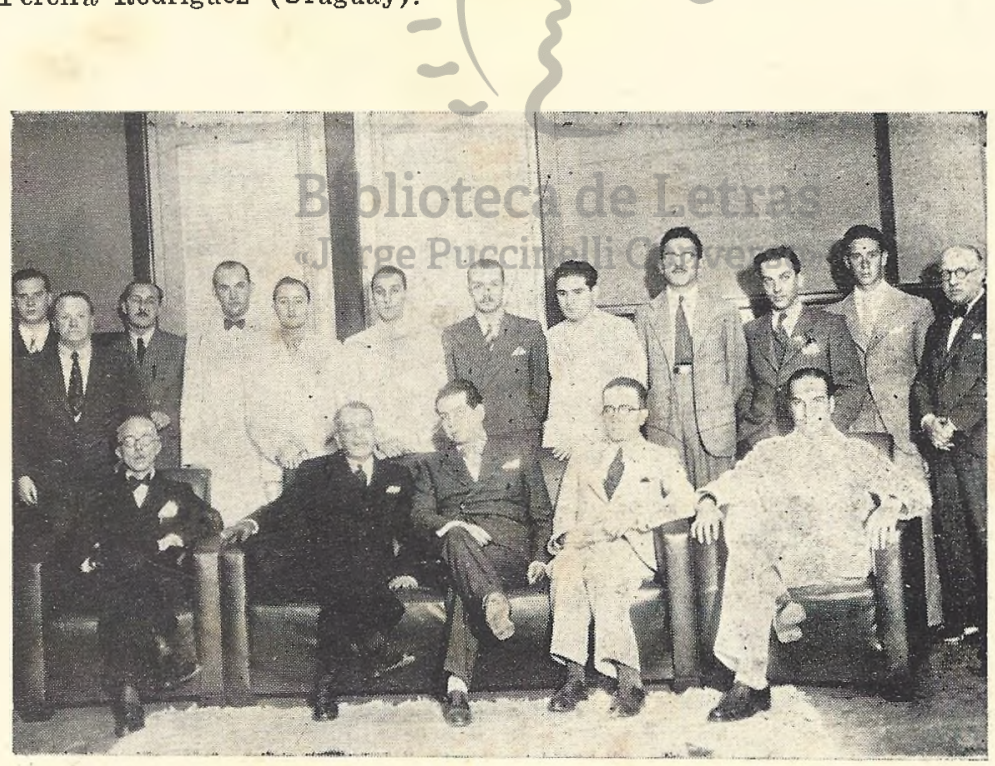

Recepción de la delegación peruaña, acompañada por el Ministro del Perí D. Luis Fernán Cisneros y por el Ministro de Educación del Uruguay. 




El Prof Manuel Beltroy (Perú) en su clase inaugural.

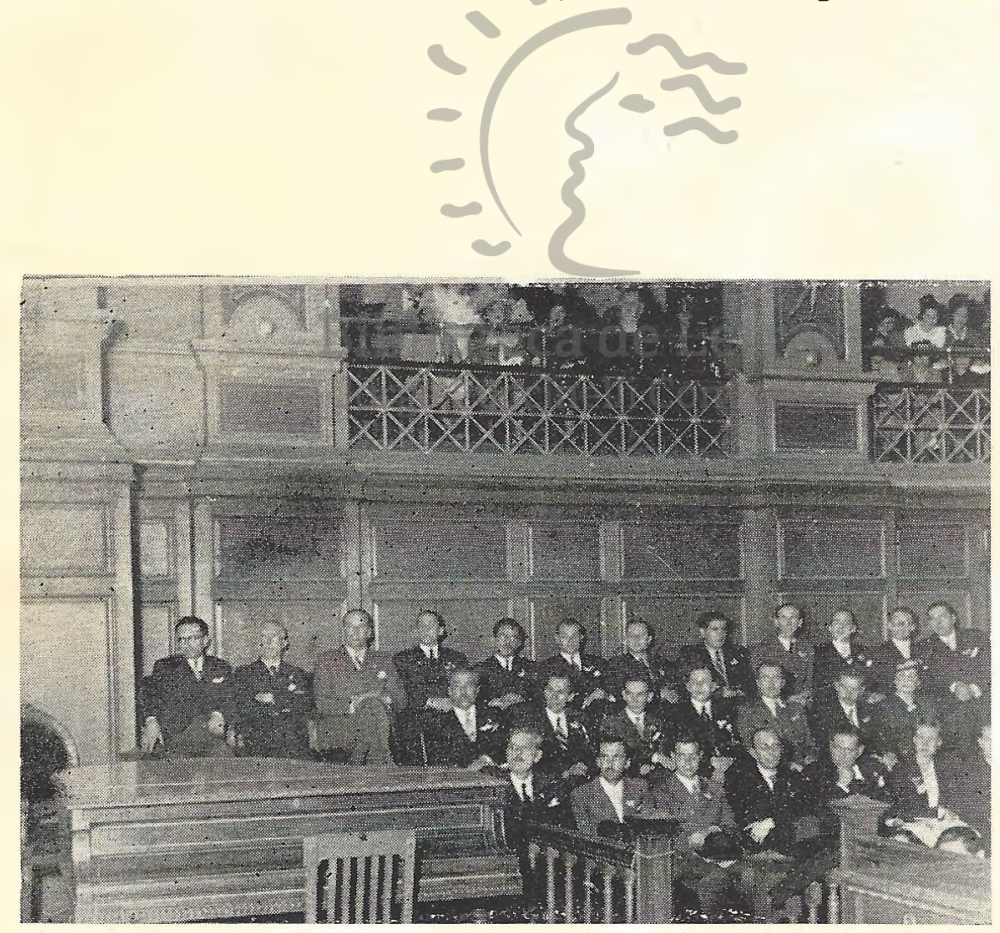

Delegaciones de los países suramericanos a Ios Cursos de Vacaciones en la ceremonia inaugural de los Cursos. 




En la ceremonia de la recepción de los profesores delegados en el "Instituto Vásquez Acevedo". El delegado peruano, Dr. Luis E. Valcárcel, contestando al discurso del Director General, Prof. Eduardo de Salterain Herrera.


Auditorio de una clase del Dr. Manuel Beltroy 